\title{
Co-Creation with Ceramic Practitioner for Improving the Marketing and Enhancing the Customer Purchase Experiences
}

\section{Yu Qinghua ${ }^{\circledR}$ \\ Yukari Nagai ${ }^{2}$ Luo Yinghuang ${ }^{3}$}

'Japan Advanced Institute of Science and Technology, Japan and Jingdezhen Ceramic Institute, Jingdezhen, China.

Email: yuqinghua@jaist.ac.jp Tel: 8109038052459

Japan Advanced Institute of Science and Technology, Japan.

Email:ynagai@jaist.ac.jp Tel:810761511706

${ }^{3}$ Hanshan Normal University, Chaozhou, China.

Email:2515@hstc.edu.cn Tel:8618879816401

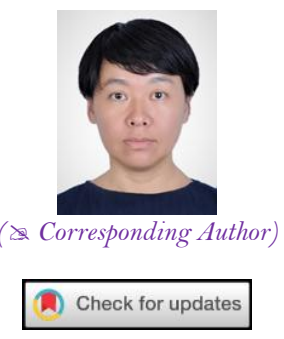

Abstract

Background: As China's porcelain capital, Jingdezhen has had a glorious history of producing ceramics for thousands of years. Nevertheless, the private ceramics sector industry is going through a development bottleneck nowadays. This research aims to utilize service design tools to co-create values with local ceramic practitioners, to improve marketing of ceramics and enhance user`s purchase experiences. Methodology: 1) Devised Likert's 7-point scale by open-ended interview approach to clarify the existing problems to collect quantitative data. 2) Analyzed the collected data by one-way ANOVA to identify the different opinions of 87 interviewed subjects. 3) Employed co-creation method and service design tools to design the online-offline service system. Findings: 1) Through qualitative and quantitative methods identified the target researched group was the young group (age range from 20 to 30). Their insights used to co-create and design an online-offline marketing system in four steps why, what, who and how. 2) Utilizing service design tools to clarify the service contents, main stakeholders, marketing models, touchpoints and how they are connected and interacting. Finally, designing an application to facilitate online purchase to improve user experience.

Keywords: Purchase experience, Online-offline, Service design tools, Marketing, Co-creation, Jingdezhen.

\section{Contribution of this paper to the literature}

This study contributes to existing literature by utilizing service design tools to co-create values with local ceramic practitioners, to improve marketing of ceramics and enhance user`s purchase experiences.

\section{Introduction}

\subsection{Background}

Jingdezhen has a long history in ceramic manufacturing; the earliest records trace back to the Han Dynasty (BC202-AD220). This study does not focus on the glorious ceramic producing history, but rather on the current status of the private sector industry. The ten state-owned porcelain factories are being restructured since 1995, (state-owned porcelain factories refer to the state-owned ceramic enterprises in Jingdezhen in the Chinese planned economy era). 60,000 to 100,000 workers were laid off from their work around the same time which seemed like the beginning of the decline of the ceramics industry in Jingdezhen. That led to the emergence of a private sector ceramic business. This study mainly focuses on small and medium-sized ceramic studios, factories and companies, to figure out how to utilize co-creation approaches with the ceramic practitioners to enhance marketing and purchase experiences using an online-offline marketing service system.

An interview and questionnaire approach used to find the already existing questions in the private sector industry in the beginning. The questionnaire was devised based on a long-term investigation in Jingdezhen (2010 2018). The collected data were analyzed by a statistical method, according to the choice of the target group (age range 20-30).

Service design tools used to achieve three simultaneous targets: (1) Research the main stakeholders; (2) Devise strategies to enhance the customer's purchase experience; (3) Improve marketing. Four steps are needed to accomplish the above: 1) why: analyzing the needs and problems of the main stakeholders of the private ceramic industry; 2) what: use service design tools to show the service content; 3) who: clarifying who is involved with the service system and how they are connected, and 4) how: defining touchpoints and the interaction with the service system to illustrate how the service works.

Co-creation is a useful approach to achieve ideal results in this research; we collaborated with local private ceramic practitioners in the design process of an online-offline service marketing platform. Co-creation belongs to the boundary of participatory design; however, the term co-creation has not been defined yet in academic circles. 
Sanders and Stappers (2008) mentioned the notion of co-creation and co-design in the growing participatory design domain. The terms of co-design and co-creation often treated similarly. One of the ideas of participatory design is to use tools to bridge between the researchers and the community members for the sake of minimizing the knowledge gaps and social-cultural differences (Sabiescu et al., 2014; Teli et al., 2017). As for co-creation, the appropriate tools should utilize in both the research and design processes. Co-creation has become the latest trend in marketing and brand development (Sanders and Stappers, 2008). Co-creation transforms design strategies from user-centred to be co-designed; the roles of both the end-users and designers have changed. Over the last decade, a user-centred design approach looked like the golden rule in the design field; the designers are always mining for the needs of end-users by interviews and other methods. Nevertheless, the end-users were not involved in the design process. The co-creation approach needs deep participation from the end-users with the designers and other stakeholders. All sitting around the same table, in the co-creation process, with their opinions become twined together iteratively (Mattelmäki, 2008). Hence, this research adopted the co-creation approach to collaborate with end-users for conducting design innovation.

\subsection{Research Questions}

This study aims to address the following two research questions:

1) How to build an online-offline service system?

2) How to enhance marketing and user purchase experience by using that online-offline service system?

To achieve this, a structure of cumulative progression proposed in this study: Section 2 illustrates the methods, including open-ended interview, questionnaire, depth interview and co-creation. Section 3 conducts quantitative data analysis. Section 4 presents the results. Section 5 utilizes service tools to clarify how the service work and how to enhance the purchase experience. Section 6 concludes, and section 7 presents limitation. Finally, acknowledgement provided in Section 8.

\section{Methods}

\subsection{Open-Ended Interview and Questionnaire}

The initial research stage utilized ethnography methods to study the practitioners from the private ceramics sector and employed an open-ended interview approach to clarify the existing problems. For this case, a longitudinal element embedded in the survey, 65 practitioners from the private sector interviewed over a period from 2010 to 2018. Dairies, pictures and records were kept to note the entire interviews (60,000-words diary - 65 videos and hundreds of photos). Each interview lasted 60 90 minutes.

According to the practitioners, the questionnaire designed to include fifteen questions using Likert's 7-point scale approach. The questionnaire designed into two dimensions: 1) the first dimension is concerned with the subsistent problems in the developing process of the private ceramics sector (questions 1 to 7), and 2) the second dimension covers the Jingdezhen ceramic marketing model (questions 8 to 15) Appendix 1.

87 subjects from the local ceramic practitioners answered the questionnaires (66 males and 21 females, aged from 20 to 60). The collected quantitative data were analyzed by SPSS software, using one-way ANOVA method to examine the subjects according to different age groups. The points of view on both investigated issues (development process and marketing models) used for the sake of finding clues to establish new hypotheses and developing new theories ( $\mathrm{Wu}, 2017)$. This research identified the target group to research by statistical analysis and designed an online-offline marketing service platform. In the end, the new design theories are generalized.

\subsection{Co-Creation}

After evaluating the quantitative data, the co-creation approach employed to design an online-offline service marketing system using service tools, such as service offering map, online-offline product marketing service blueprint. Out of the previous practitioners, 12 subjects were chosen in this process, eight females and four males, aged from 25 to 30 with ceramic design or art background. The focus groups organized to discuss; the needs and problems of the stakeholders in this research - identify the service contents - clarify the main stakeholders understand the operating methods of the service system.

\section{Quantitative Data Analysis}

Developing a design questionnaire from two levels, the first level problems are concern the existing problems in the Jingdezhen private ceramics industry, including the shortage of funds in manufacture process, the need for design innovation, design plagiarism, intellectual property protection, brand development planning, expansion of production scale, and the government support, totally 7 items, in order to analyze the problems encountered during the development of the private ceramics industry in Jingdezhen. The second level problems are focus on the marketing of the ceramic product of Jingdezhen, including the traditional store sales model, store direct sales and agent sales model, internet marketing for the development of ceramic enterprises, online selling and offline taking delivery model, online ceramic culture promotion, the government integrate online-offline sales service platform, self-media marketing model and unified price in direct sales or agency sales, which has eight issues.

The distribution of the questionnaire was targeted, Jingdezhen ceramics practitioners were the primary research target groups, including potters, ceramists, artisan, business owners and ceramic sales staff, and so forth. The 87 subjects (66 males and 21 females) answered the questionnaires, on the age level, 41 subjects aged 21-30, accounting for $47.13 \%, 35$ subjects aged 31-40, accounting for 40.23\%, and subjects aged 41-50 are 8 People, accounting for $9.2 \%$; 3 people surveyed between the ages of $51-60$, accounting for $3.45 \%$. The respondents of $20-30$ and $31-40$ age grades are the main body of this research who are the main force of the private ceramics industry in Jingdezhen. 


\subsection{Research Hypotheses}

H1: Through long-term investigation, many problems found in the Jingdezhen private ceramics sector. The ones causing most of the concerns include; design plagiarism, brand development, product design innovation and shortage of funds. Nevertheless, different age groups of practitioners had different consideration of the importance of the existing problems.

H2: The traditional store sales model is still the mainstream in Jingdezhen. However, the rapid development of Internet marketing methods has been influencing Jingdezhen's ceramics marketing hugely in recent years; since internet marketing has a wide range of development prospects. Establishing an online-offline marketing platform in new business sales is necessary. As to Jingdezhen ceramic marketing, applying service design strategy to build an online-offline service platform is necessary to help integrating manufacture and sales resources as well as improving purchase experience. This is considered the best way to utilize the limited production and design resources. As for the marketing model, subjects from different age groups have different opinions regarding the traditional and networked marketing model. Tounger subjects are more willing to accept internet marketing models.

\subsection{One-Way ANOVA Analysis of $\mathrm{H} 1$}

Seven questions included in the first level of the questionnaire, and then one-way ANOVA method was used to analyze the answers. Testing the Homogeneity of Variances is shown in Table 1 the Levene Statistic Values are $1.72,0.96,1.28,1.08,0.82,0.18$ and 0.31 . All the significance values are greater than 0.05 , indicating all have not reached a significant level. Thus, the null hypothesis should be accepted, which indicates that the variances of the two groups of samples are not significant and the homogeneity of variance is not violated (Wu, 2017).

\begin{tabular}{c|c|c}
\multicolumn{3}{c}{ Table-1. Test of homogeneity of variances. } \\
\hline \multicolumn{3}{c}{ Test of homogeneity of variances } \\
\hline & Levene statistic & Sig. \\
\hline A1 & 1.72 & .17 \\
\hline A2 & .96 & .42 \\
\hline A3 & 1.28 & .29 \\
\hline A4 & 1.08 & .36 \\
\hline A5 & .82 & .48 \\
\hline A6 & .18 & .91 \\
\hline A7 & .31 & .82 \\
\hline \multicolumn{2}{|l}{} \\
Source: Field survey, 2019.
\end{tabular}

The variance summary in Table 2 shows that the significance values of the seven issues are also greater than 0.05 , not reaching a significant level again, implying the null hypothesis. Combining the results of Table 1 and Table 2 concludes that the subjects from different age groups do not have different opinions regarding the seven issues. Thus, the result does not validate the problems mentioned in Hypothesis 1. Still there are differences in the opinions of the age ranges regarding the problems in the Jingdezhen private ceramics sector.

\begin{tabular}{|c|c|c|c|}
\hline \multicolumn{4}{|c|}{ ANOVA } \\
\hline & & $\mathbf{F}$ & Sig. \\
\hline \multirow{3}{*}{$\mathrm{A} 1$} & Between Groups & .50 & .69 \\
\hline & Within Groups & & \\
\hline & Total & & \\
\hline \multirow{3}{*}{$\mathrm{A} 2$} & Between Groups & .21 & .89 \\
\hline & Within Groups & & \\
\hline & Total & & \\
\hline \multirow{3}{*}{ A3 } & Between Groups & 1.69 & .18 \\
\hline & Within Groups & & \\
\hline & Total & & \\
\hline \multirow{3}{*}{$\mathrm{A} 4$} & Between Groups & .84 & .48 \\
\hline & Within Groups & & \\
\hline & Total & & \\
\hline \multirow{3}{*}{ A5 } & Between Groups & 1.12 & .35 \\
\hline & Within Groups & & \\
\hline & Total & & \\
\hline \multirow{3}{*}{ A 6} & Between Groups & .32 & .81 \\
\hline & Within Groups & & \\
\hline & Total & & \\
\hline \multirow{3}{*}{ A 7} & Between Groups & .81 & .49 \\
\hline & Within Groups & & \\
\hline & Total & & \\
\hline
\end{tabular}

\subsection{One-Way ANOVA Analysis of $\mathrm{H} 2$}

The second level of the questionnaire has a total of eight questions related to marketing ceramic products in Jingdezhen. One-way ANOVA method also used to test the data here; the Test of Homogeneity of Variances is in Table 3. Levene Statistic Values are 1.28, 1.37, 0.67, 1.22, 1.63, 0.20, 1.73 and 0.65. All values are all greater than 
0.05so have not reached any significant level. Again, we should accept the null hypothesis, that the variance between the two sample groups is not significant and the homogeneity of variance is not violated.

\begin{tabular}{c|c|c}
\multicolumn{3}{c}{ Table-3. Test of homogeneity of variances. } \\
\hline \multicolumn{3}{c|}{ Test of homogeneity of variances } \\
\hline & Levene statistic & Sig. \\
\hline B1 & 1.28 & .29 \\
\hline B2 & 1.37 & .26 \\
\hline B3 & .67 & .57 \\
\hline B4 & 1.22 & .31 \\
\hline B5 & 1.63 & .19 \\
\hline B6 & .21 & .89 \\
\hline B7 & 1.72 & .17 \\
\hline B8 & .65 & .58 \\
\hline Source: Field survey, 2019. &
\end{tabular}

The variance summary in Table 4 indicates that the ninth topic: "The store direct sales and agent sales model have broad development of prospects", is significant $(\mathrm{P}=0.01<0.05)$, and this must reject the null hypothesis and accept the opposite hypothesis. Accordingly, the respondents from different ages groups have different perspectives regarding the development broad prospects of store direct sales and agent marketing models. The significance values of the other seven questions are all greater than 0.05 , so not reaching any significant level. Therefore, the null hypothesis should be accepted that among the subjects from different age groups, there are no differences.

\begin{tabular}{|c|c|c|c|}
\hline \multicolumn{4}{|c|}{ ANOVA } \\
\hline & & $\mathbf{F}$ & Sig. \\
\hline \multirow{3}{*}{ B1 } & Between Groups & .10 & .96 \\
\hline & Within Groups & & \\
\hline & Total & & \\
\hline \multirow{3}{*}{$\mathrm{B} 2$} & Between Groups & 3.90 & .01 \\
\hline & Within Groups & & \\
\hline & Total & & \\
\hline \multirow{3}{*}{ B3 } & Between Groups & .89 & .45 \\
\hline & Within Groups & & \\
\hline & Total & & \\
\hline \multirow{3}{*}{ B4 } & Between Groups & .62 & .60 \\
\hline & Within Groups & & \\
\hline & Total & & \\
\hline \multirow{3}{*}{ B5 } & Between Groups & .92 & .44 \\
\hline & Within Groups & & \\
\hline & Total & & \\
\hline \multirow{3}{*}{ B6 } & Between Groups & .10 & .96 \\
\hline & Within Groups & & \\
\hline & Total & & \\
\hline \multirow{3}{*}{$\mathrm{B} 7$} & Between Groups & .51 & .68 \\
\hline & Within Groups & & \\
\hline & Total & & \\
\hline \multirow{3}{*}{ B8 } & Between Groups & .11 & .96 \\
\hline & Within Groups & & \\
\hline & Total & & \\
\hline
\end{tabular}

Table-5. Multiple comparisons.

\begin{tabular}{|c|c|c|c|c|}
\hline \multicolumn{5}{|c|}{ Multiple comparisons } \\
\hline \multicolumn{5}{|c|}{ Dependent variable: $\mathrm{B} 2$} \\
\hline \multicolumn{5}{|c|}{ Scheffe } \\
\hline \multirow[t]{3}{*}{ (I) Age } & (J) Age & Mean difference (I-J) & Std. Error & Sig. \\
\hline & $20-30$ & $1.770^{*}$ & .539 & .008 \\
\hline & $41-50$ & $-1.770^{*}$ & .539 & .008 \\
\hline
\end{tabular}

The ninth topic found significant, which needs the further investigation to identify the differences between the age groups. Multiple comparisons using Scheffe method utilized for analyzing, from the pairwise Scheffe post-hoc comparisons Table 5. In the third column of the Mean Difference (I-J) shows the different values from the paired 
comparisons between the two groups. The mean difference value is -1.770 , between the $20-30$ age group and the 41-50 age group which indicates that the 20-30 age group is significantly lower than the 41-50 age group in the average score of the ninth issue. This means the young group hold negative attitudes to the store direct sales and agent sales model than the older group.

\section{Results of Research Hypotheses}

\subsection{Hypothesis 1}

For the first level questions, there was no difference between the views among the ceramic practitioners regardless of their ages. This is mainly because all the subjects were ceramic professionals from Jingdezhen with enough knowledge about Jingdezhen ceramic industry and its troubles. The subjects consider among these problems, design plagiarism, brand development and design innovation are the most concerning. Through longterm investigation in Jingdezhen, we learnt, that the ceramics enterprises have had no leaders, no established marketing management or operating mechanism. Since the ten state-owned porcelain factories closed down, a lowend survival and developing mode is being adapted in the local private ceramics sector.

The solution is to give full play to the government functions and establish reasonable industry rules to settle down trouble effectively. At the same time, the government should: organize design and production - pay attention to the design innovations and brand development strategies - enhance the popularity of Jingdezhen ceramic products by establishing strong brands.

\subsection{Hypothesis 2}

The second level questions were about ceramic marketing in Jingdezhen. Except for the ninth item, there is no difference between the points of view of the subjects from different age groups. The ninth question is whether there is a wide range of development prospects for store direct sales and agent business models. Among them, the subjects of the 20-30 age group have a negative attitude towards this issue, while the subjects of the 41-50 age group hold a positive point of view. This is probably because Internet sales model has been rising in Jingdezhen in recent years. Young ceramic practitioners are more receptive to emerge internet sales models. While for older groups, traditional sales models are more attractive. In fact, at present, the leading group to apply the internet marketing model in Jingdezhen is the 20-30 age group; they always use all internet marketing models to sell ceramic products to introduce ceramic craft and culture, providing excellent user experience in the purchasing process to enhance the user viscosity, for the sake of expanding products sales.

\section{Discussions of Service Marketing System}

Quantitative data analysis is conducted with target research population from the 20-30 age group. We used cocreation approach to collaborate with the ceramic practitioners in designing a service system to improve ceramics marketing and purchase experiences. According to the survey data from a research report of Jingdezhen ceramic institute, currently, $20 \%$ of the ceramic practitioners hope to maintain their status; $5 \%$ of them plan to change their business; $17.5 \%$ of them have not decided while the majority $(57.5 \%)$ want to move towards brand developing direction. The data also shows the desire of the most ceramic practitioners to change their development model.

How to develop the private ceramic sector to improve ceramic marketing and enhance purchase experiences? The current problems are mainly due to the government policy; because the reform of the ten state-owned porcelain factories led to an unprecedented increase in people's leaving and production pressure. In the 1990s, the production of porcelain began to fall and excellent artisans and designers started to drain. The original foundation collapsed and ceramic exports, as well as domestic sales plummeted (Shen, 2004). The measures taken by the Jingdezhen government were completely market-oriented, but the results proved unsuccessful. In order to rectify the path of development, the Jingdezhen government has explored carried out various countermeasures (Liu and Chen, 2008). At the moment, the Jingdezhen government still regards the development of private ceramics sector as its core annual issue. Through interviews to get the development strategies: The first step is to take the lead from the government to integrate resources towards private ceramics studios and factories first to develop brand strategies. To create brands in the form of joint-stock companies with a unified brand approach, cooperative ceramic factories need, completing orders on time, while guaranteeing both quality and quantity. Design agencies are needed, hiring professional designers to develop new ceramics and service system. The second step is to implement the policy of online-offline marketing to maximize economic benefits. That way, ceramic factories can fulfil sales commissions and year-end dividends strategy to generate income.

How to achieve this goal can be demonstrated here in four steps (why, what, who and how), as that will show in this rest of this section

\subsection{The First Step "Why”}

\subsubsection{The Existing Problems}

"Why": Analyzing the needs and problems of the main stakeholders in the private ceramic sector. The main stakeholders in this research include ceramists, potters, artisans, salespeople and entrepreneurs. We conducted interviews with them to find out the needs and existing problems in their business and planned the design strategy according to their needs.

1). For the ceramists and porters, who mainly focus on two issues; first, the government support, the other is how to eliminate plagiarism. They need support from the government because ceramists and porters always suffer crises in their career development mostly due to the lack of a platform to study new ceramic craft, designs and art trends. Design plagiarism is another problem they are suffering in their business developing process. The ceramists and porters are the leading force in implementing ceramics innovation. Hence, they should be acquainted with the recent international ceramic innovations, and also need help to eliminate plagiarism.

2). For the artisans, Jingdezhen has a long history in ceramic manufacture, and the private ceramics industry has also achieved industry division of labour; in Jingdezhen, ceramic craft includes several types of work as rolling 
over, throwing, trimming, painting and firing Figure 1. Using interviews, we identified their needs and existing problems; the primary problem is the lack of funding; the long-term low-end development model makes it challenging for these ceramic workshops on surviving and can barely maintain daily operation.

3). For the sellers, the target research group in this study was 20 to 30 years old. We conducted in-depth interviews to learn about their business and marketing methods also the principal internet marketing users. Some of their problems are: 1) Brand development awareness is weak due to the lack of funds, so online marketing is heading towards a crisis. The number of customers has been declining; the customers' interests are changing rapidly and cannot be caught promptly. 2) Orders and ceramics manufacturers are not well connected; the supply shortage is sometimes exposed. Moreover, the whole selling process is complicated, distributors' payments are always late, which easily causes a financial deficit for those online marketing companies.
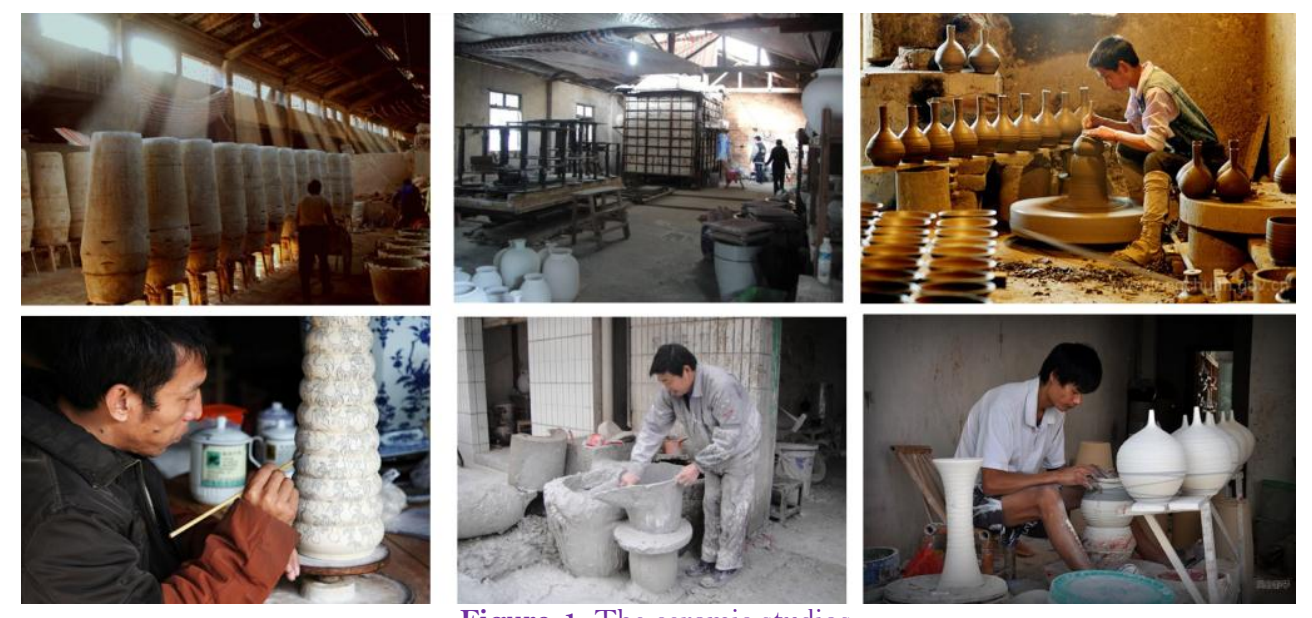

Source: Field survey, 2018

Figure-1. The ceramic studios.

4). For the entrepreneurs, the information needed to manage such companies is incomplete, and a manager ends up with the company into an out-of-stock situation or excessive production with products backlog, as well as the company's investment in producing is still high, product innovations are not enough and usually suffering from design plagiarism.

\subsubsection{How to Deal With these Problems}

How to deal with these problems for ceramic practitioners in their developing process, we put forward the following strategies.

The ceramic practitioners have been paying more attention to design innovation, design plagiarism and brand development in their developing process. First, design innovation, the government should build a service platform for ceramic practitioners to provide a chance to learn and improve their design level and professional skills. The government can hold an international ceramic workshop inviting domestic and international ceramic artists to collaboration. Second, design plagiarism, it has been perplexing the ceramic industry for years. To eradicate plagiarism, the local government should issue relevant regulations to restrict and punish design plagiarism as well as promote the development of ceramic design innovations. Third, nowadays developing strategy of the brand must be adapted as in European countries. Jingdezhen ceramic brands have a short history which led to low-end competition model in marketing. However, brand building is expensive and could not afford by most of the ceramic practitioners. The local government must take leadership in the brand-building process and provide legal and economic guidance to practitioners.

Finally, marketing method, we should integrate into online-offline ceramic marketing service platforms to promote ceramic culture. We designed an online-offline ceramic marketing system for ceramic recommendations, customization and crowdfunding to help sellers and entrepreneurs improve their marketing.

\subsection{The Second Step "What"}

A map for service offering is a useful tool to show the service content in this research. From Figure 2 online stores contain five major functional modules: 1) Ceramic recommendations: utilizing big data technology to analyze consumers' preference and suggest recommended ceramic products; 2) Ceramic customization: designers and manufacturers depend on customer`s needs to provide one-on-one ceramic customization services. Normann (2001) pointed out that the business environment continues to shift from a goods-dominant environment towards a service-dominant one (Normann, 2001).

Ceramic customization is a new direction to integrate ceramic products and service. 3) Ceramic crowdfunding: ceramic crowdfunding services offer opportunities for the new entrepreneurs in the ceramic business to use internet dissemination characteristics as well as artists or individuals to show their creativity to the public for financial assistance. 4) Sharing community: registered users can publish comments posting about their purchase and experience. 5) User communication: to provide online instant chat capability, so that, consumers can communicate quickly and promptly. Those services integrate design, manufacture resources and sales to maximize production benefits. Offline service support logistics, customer service and network technical support as well as on-going order processing. 


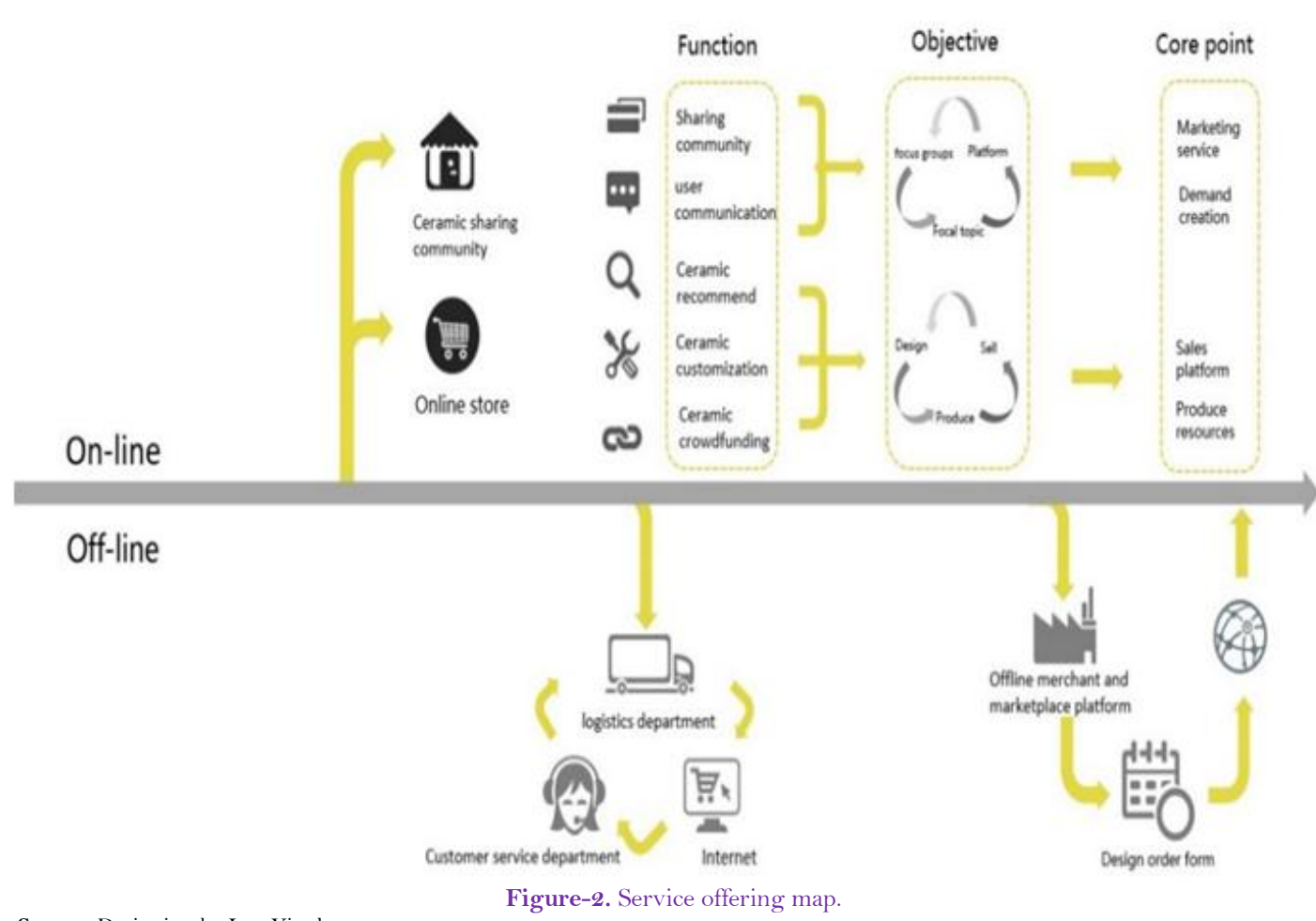

Source: Designing by Luo Yinghuang.

Figure-2. Service offering map.

The profit sources of the online sales platform are as follows: 1) Ceramic sales commission; 2) Platform promotion fee; 3. Business admission fee; 4. Brand marketing service fee.

\subsection{The third step "Who"}

The designed online-offline platform shows the main stakeholders and how are they connected. Stakeholders are groups or individuals who have a stake in the conduct and consequences of the business operation. Figure 3 shows the stakeholders and marketing model throughout the service system. The stakeholders in this study are: customer service departments - customers - logistics departments - ceramic studios - factories - offline display promotion platforms - offline merchant and marketplace platforms - production resources. This can be divided into two parts: online and offline, the online aims to improve purchase service experience, reduce transactions, optimize service experience. Offline provides product design, manufacture, transportation and exhibition services. Users would access the online marketing service from a mobile terminal and the webpage terminal.

All the stakeholders in this research interact with each other and the whole system in funds, production and information flows, represented by the three lines in Figure 3. The production flow connects production resources, ceramic studios, factories, logistics and customer. The offline platform should support the producing resources and collaborate with ceramic studios, factories to manage manufacturing processes. The logistics department should contact the ceramic studios and factories responsible for delivering the ceramics to customers. The funds flow is the critical factor in the online-offline system, which connects all the business stakeholders to the customer service department. Information flow is another vital factor in the system connecting all the Stakeholders. Through information flow, the customer can get excellent purchase experience relying on the collaboration of all the other stakeholders.

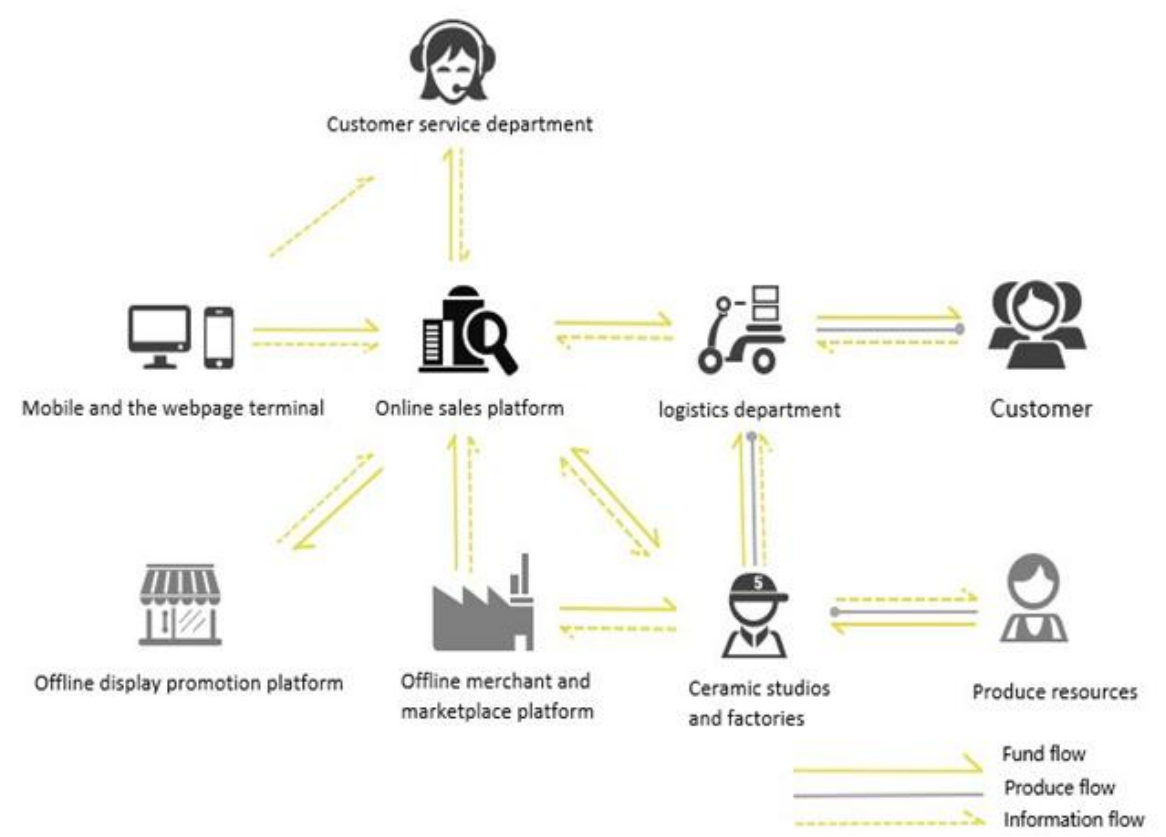

Figure-3. Stakeholders and online-offline model.

Source: Designing by Luo Yinghuang.

\subsection{The Fourth Step "How"}

Employed service blueprint in this research to study touchpoints and interaction in the online-offline marketing service system; the purpose is to analyze how the service work. We are co-creation with stakeholders to 
design service blueprint; the first step is to design the layers, to clarify how many layers include in the onlineoffline ceramics marketing service system. We conducted a focus group discussion, and at last, designed six layers in this service blueprint Figure 4: evidence, customer journey, touchpoints, online employee contact, backstage employee contact, and support processes. 1). The evidence layer is to show the visual and physical evidence in browser the web, payment informant, and delivery service; 2). Customer journey is to illustrate the process from visit website to get the ceramics; 3). Touchpoints are to identify the multi-touch points in the whole service process, including interface, webpage, charging system, message; employee and deliveryman; 4). Online employee contact is to demonstrate the selling process, from answering customer's questions, checking inventory, confirming the address to provide delivery time; 5). Backstage employee contact is to execute the marketing service, the backstage staff will respond to chat questions, utilizing the inventory management system to check the ceramics, and execute the order, and 6). Support processes are related to technical support, such as using big data to analyze web visitor, to recommend ceramic product depending on the visitor`s preference. The web browser, payment process, order fulfilment, and delivery service company are the support processes, providing support for the whole marketing system.

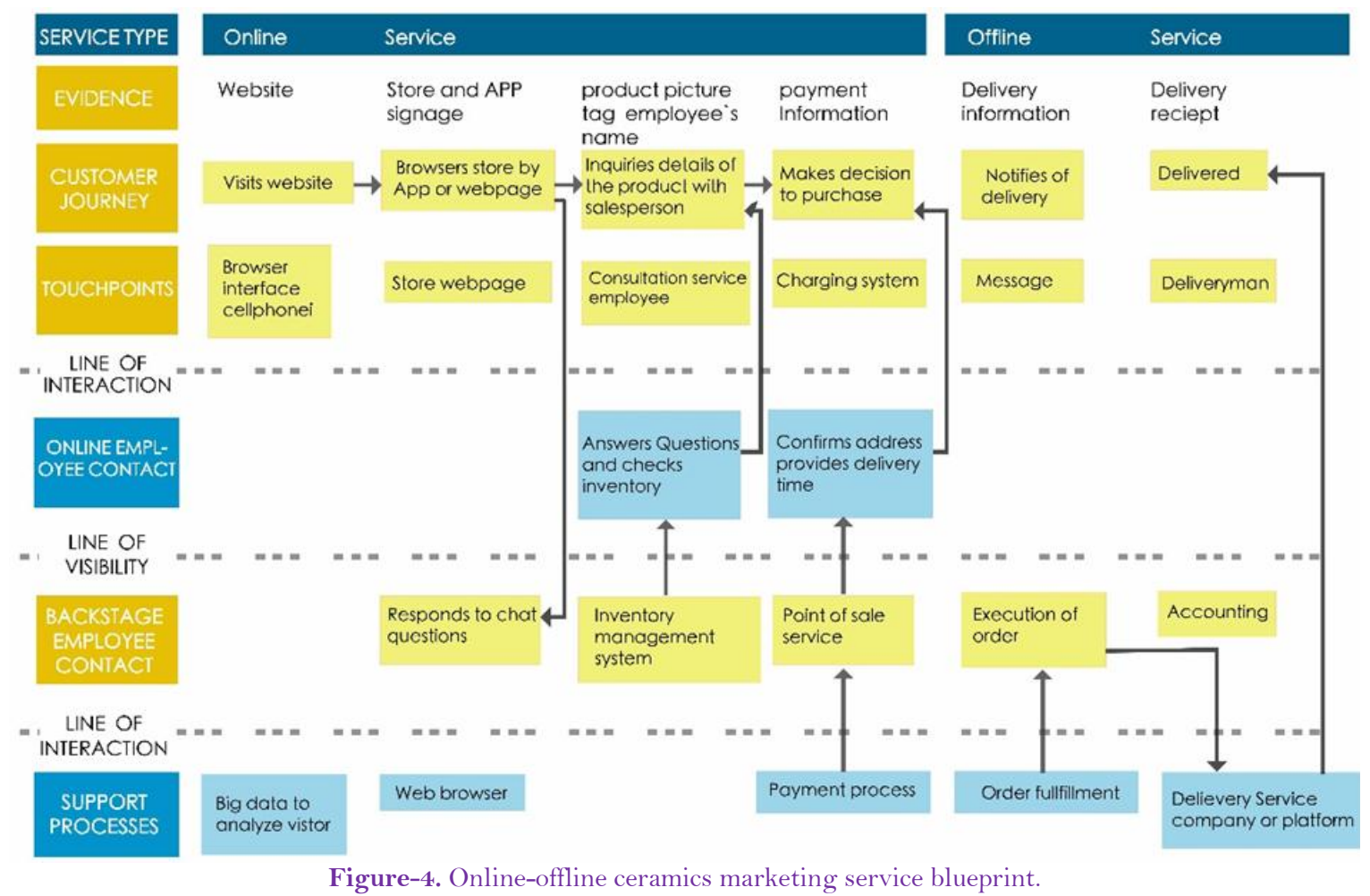

Source: Designing by Luo Yinghuang.

\section{5. "MI" Application}

In order to improve the online-offline purchase experience, we designed a user interface, for mobile and web applications, as shown in Figure 5. The mobile application, we called: MI (受), which means of Chinese is to "find". The customer can use the application or webpage to search for the ceramics he wants; big data techniques can autorecommend depending on the customer's preferences. Additionally, customers can find others with common interests using the online commenting module. The application also introduces information related to ceramic, for in-depth understanding of the ceramic culture and craft.
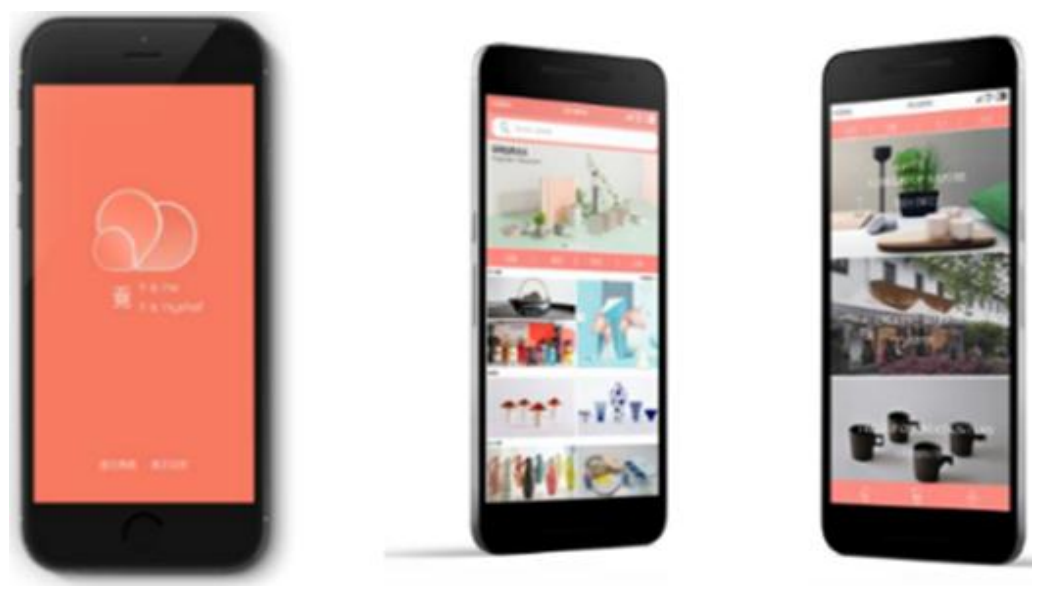

Source: Designing by Luo Yinghuang.

The design style of the interface used warm tone; standard colors are red, grey scheme. In terms of functional modules, it provides several major functions as product categories, promotion, sales and user evaluation. For different modules made a reasonable function division Figure 6: 1) the product category shows the different ceramics types as tableware, wine sets, tea sets, coffee sets, vases. 2) The promotion module includes packaging, transportation and other different information to improve the user experience; 3) The sales module provides an online purchasing service; and 4) In the user review area ( $Q \& A)$, registered users can obtain bonus points by asking and answering questions in order to increase the users' viscosity and knowledge. The user needs to register for 
shopping online; the registered user can enjoy convenient services. For example, a user can choose custom service; the designer will work according to individual customer requirements to design for them; the design fees also listed on the webpage. Ceramic crowdfunding service can also be operated and viewed from mobile applications. The user review area is a type of online participation model, to express knowledge about ceramic and to know more about the culture and craft. Additionally, it can expand social relationships with others having the same interests in the ceramic domain.

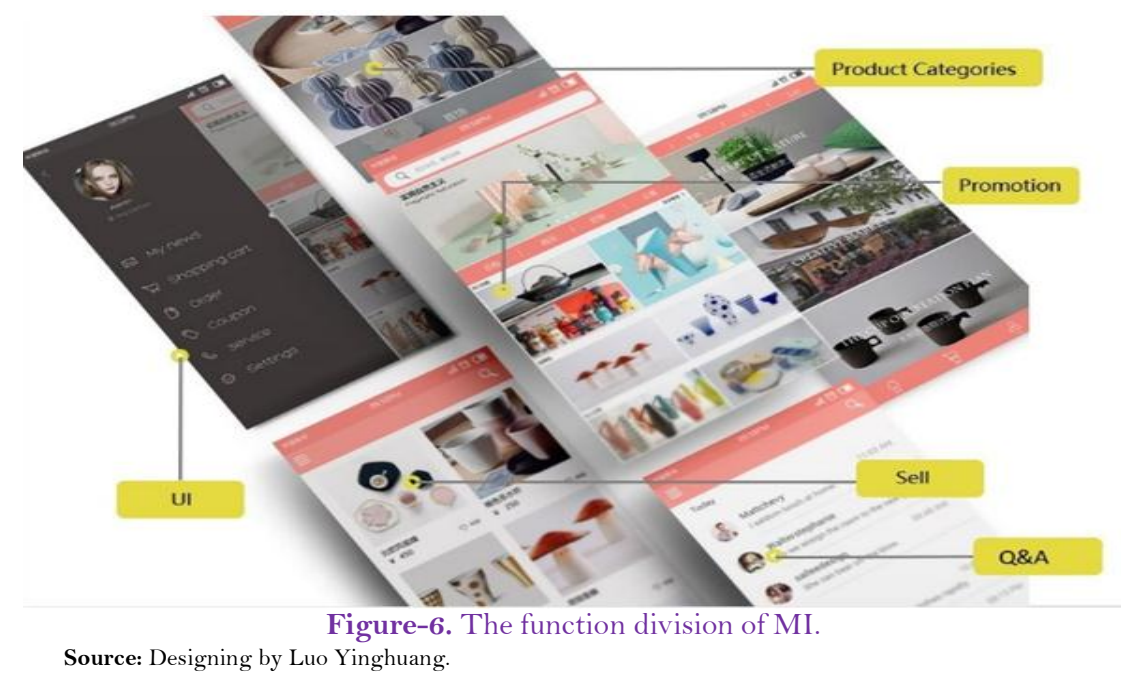

In conclusion, integrating resources by local government, to establish an online-offline service marketing platform to promote the ceramic culture of Jingdezhen, provide multiple sales services, enhance user viscosity, and offer customers outstanding online shopping experience. The importance of the customer experience has been recognized by service organizations (Zomerdijk and Voss, 2010; Patrício et al., 2011). Enhancing customer experience, customer satisfaction and loyalty can create a new value, which is the most critical development way for Jingdezhen private ceramic sector.

\section{Conclusions}

Qualitative and quantitative methods were used to study the target subjects, utilizing open-ended interviews, in-depth interviews, focus groups and questionnaires to collect qualitative and quantitative data. One-way ANOVA analysis was used to identify the age group from 20 to 30 who had disagreed with the other groups about traditional ceramics marketing. Co-creation approach was followed with that age group to design an online-offline marketing system.

We employed service design tools and co-created with the ceramic practitioners to design service offering map and service blueprint for learning how the service works and how to enhance the customers' experience. We tried to offer an outstanding user experience in the purchasing process by providing unique services. The user review area can enhance the conversation between ceramic sellers and customers and further improve the user experience and user viscosity. Additionally, spreading ceramic culture online will also help increase marketing.

\section{Limitation}

The limitation of this study is that the current concept still stays at the design stage. However, this design strategy has been awarded by the China Construction Bank, the China University Innovation, Entrepreneurship Education Alliance and the National University Innovation and Venture Investment Service Alliance. However, the implementation of the project still needs the support of the local government in Jingdezhen since the actual implementation of this project is estimated to take quite a long time.

\section{References}

Liu, S.Q. and W.H. Chen, 2008. A study on structure convention characteristic of Jingdezhen ceramics characteristic industry colony, 85(12): 60-63.

Mattelmäki, T., 2008. Probing for co-exploring. Co-Design, 4(1): 65-78.Available at: https://doi.org/10.1080/15710880701875027.

Normann, R., 2001. Reframing business: When the map changes the landscape. New Sussex: Wiley, Chichester.

Patrício, L., R.P. Fisk, J. Falcão e Cunha and L. Constantine, 2011. Multilevel service design: From customer value constellation to service experience blueprinting. Journal of Service Research, 14(2): 180-200.Available at: https://doi.org/10.1177/1094670511401901.

Sabiescu, A.G., S. David, I. Van Zyl and L. Cantoni, 2014. Emerging spaces in community-based participatory design: Reflections from two case studies. In Proceedings of the 13th Participatory Design Conference: Research Papers. ACM, 1: 1-10.

Sanders, E.B.-N. and P.J. Stappers, 2008. Co-creation and the new landscapes of design. Co-design, 4(1): 5-18.Available at: https://doi.org/10.1080/15710880701875068.

Shen, J.L., 2004. The itch and pain of Jingdezhen for a thousand years after a storm of "Fengdu", Xinmin Weekly.

Teli, M., A. Di Fiore and V. D’Andrea, 2017. Computing and the common: A case of participatory design with think tanks. CoDesign, 13(2): 83-95.Available at: https://doi.org/10.1080/15710882.2017.1309439.

Wu, M.L., 2017. Questionnaire statistical analysis pragmatic: SPSS operation and application. China Chongqing University Press. pp: 290.

Zomerdijk, L.G. and C.A. Voss, 2010. Service design for experience-centric services. Journal of Service Research, 13(1): 67-82.Available at: https://doi.org/10.1177/1094670509351960. 


\section{Appendix 1}

\begin{tabular}{|c|c|c|c|c|c|c|c|}
\hline \multirow[t]{2}{*}{ Topics } & $\begin{array}{l}\text { Extremely } \\
\text { disagree }\end{array}$ & $\begin{array}{l}\text { Strongly } \\
\text { disagree }\end{array}$ & Disagree & Neutral & Agree & $\begin{array}{l}\text { Strongly } \\
\text { agree }\end{array}$ & $\begin{array}{l}\text { Extremely } \\
\text { agree }\end{array}$ \\
\hline & 1 & 2 & 3 & 4 & 5 & 6 & 7 \\
\hline \multicolumn{8}{|l|}{$\begin{array}{l}\text { 1. The shortage of funds in the } \\
\text { manufacture process }\end{array}$} \\
\hline \multicolumn{8}{|l|}{$\begin{array}{l}\text { 2. It is necessary to carry out } \\
\text { design innovation }\end{array}$} \\
\hline \multicolumn{8}{|l|}{$\begin{array}{l}\text { 3. Frequently encountered } \\
\text { product plagiarism }\end{array}$} \\
\hline \multicolumn{8}{|l|}{$\begin{array}{l}\text { 4. Local ceramic practitioners } \\
\text { have intellectual property } \\
\text { protection awareness }\end{array}$} \\
\hline \multicolumn{8}{|l|}{$\begin{array}{l}\text { 5. It is necessary to establish a } \\
\text { brand development plan }\end{array}$} \\
\hline \multicolumn{8}{|l|}{$\begin{array}{l}\text { 6. It is necessary to expand the } \\
\text { production scale }\end{array}$} \\
\hline \multicolumn{8}{|l|}{$\begin{array}{l}\text { 7. The government has not } \\
\text { supported private ceramic } \\
\text { enterprises properly }\end{array}$} \\
\hline \multicolumn{8}{|l|}{$\begin{array}{l}\text { 8. traditional store sales model } \\
\text { is the mainstream }\end{array}$} \\
\hline \multicolumn{8}{|l|}{$\begin{array}{l}\text { 9. The store direct sales and } \\
\text { agent sales model have broad } \\
\text { development prospects }\end{array}$} \\
\hline \multicolumn{8}{|l|}{$\begin{array}{l}\text { 10. Internet marketing is } \\
\text { necessary for the development } \\
\text { of ceramic enterprises }\end{array}$} \\
\hline \multicolumn{8}{|l|}{$\begin{array}{l}\text { 11. online shopping and offline } \\
\text { store pick-up mode are feasible }\end{array}$} \\
\hline \multicolumn{8}{|l|}{$\begin{array}{l}\text { 12. online platforms to promote } \\
\text { ceramic culture can enhance } \\
\text { ceramic products marketing }\end{array}$} \\
\hline \multicolumn{8}{|l|}{$\begin{array}{l}\text { 13. It is necessary for the } \\
\text { government to integrate } \\
\text { online-offline r ceramic } \\
\text { marketing service platforms. }\end{array}$} \\
\hline \multicolumn{8}{|l|}{$\begin{array}{l}\text { 14. Self-media marketing model } \\
\text { is necessary }\end{array}$} \\
\hline $\begin{array}{l}\text { 15. The same product needs a } \\
\text { unified price in direct sales or } \\
\text { agency sales }\end{array}$ & & & & & & & \\
\hline
\end{tabular}

Source: Field survey, 2019.

Citation | Yu Oinghua; Yukari Nagai; Luo Yinghuang (2019). CoCreation with Ceramic Practitioner for Improving the Marketing and Enhancing the Customer Purchase Experiences. Asian Business Research Journal, 4: 44-53.

History

Received: 20 September 2019

Revised: 29 October 2019

Accepted: 4 . December 2019

Published: 2 January 2020

Licensed: This work is licensed under a Creative Commons

Attribution 3.0 License (cc)

Publisher: Eastern Centre of Science and Education
Acknowledgement: The authors wish to thank Luo Yinghuang for helping to design the figures in this article. They also thank the anonymous reviewers for the valuable constructive suggestions.

Funding: This research was supported by the Art General Project of 2018 National Social Science Fund (18BG118, Research on the History of Chinese Traditional Tool Design Concepts).

Competing Interests: The authors declare that they have no conflict of interests.

interests.

Transparency: The authors confirm that the manuscript is an honest, accurate, and transparent account of the study was reported; that no vital features of the study have been omitted; and that any discrepancies from the study as planned have been explained.

Ethical: This study follows all ethical practices during writing.

Eastern Centre of Science and Education is not responsible or answerable for any loss, damage or liability, etc. caused in relation to/arising out of the use of the content. Any queries should be directed to the corresponding author of the article. 